\title{
Challenges in Estimating Quantitative Precipitation Estimation (QPE) Using Weather Radar Observation Over the Mountainous Country of Nepal
}

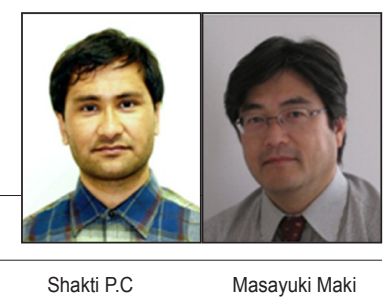

Abstract: South Asian country Nepal characterizes a complex mountain range in this world. The country's population density is increasing along with rapid growth of population especially over mountainous cities, southern hills and the Terai. On the other hand, a number of fatal natural calamities, such as flash flooding and landslides raised by clutter intensive rainfall, have been increasing since the last decade. To deal with such water hydro meteorological disasters, accurate information on spatial and temporal variation of rainfall distribution is very important. In Nepal, the amount of rainfall has been obtained from limited rain gauge networks, which may leads to many errors in making a Quantitative Precipitation Estimation (QPE). Weather radar observations have recently been highlighted as an alternative option for estimating the spatial and temporal distribution of precipitation across specified time intervals. However, estimating rainfall from radar observation has its own challenges, especially over a mountainous country like Nepal.

Another mountainous country Japan is well known for using weather radar observation to make QPE product. Different types of weather radar have been used to record, monitor and forecast precipitation in Japan for both operational and research purposes. A high level research work has also been done on this field. The high spatial and temporal (250-m and 1-min) QPE product obtained from the radar observation is available for the public. It shows good harmony with ground data in the flat and mountain areas of Japan. Though Nepal and Japan are located in different regions, both countries represent complex mountain regions and have been facing natural disaster caused by extreme rainfall. In Nepal, weather radar observation for estimating precipitation amounts has not started on an operational basis till date. Hence, sharing knowledge and skills from Japan's research on weather radar observation would play a key role to achieve the radar based QPE product in Nepal. Therefore, we discuss about the challenge in obtaining QPE product, considering an example of the progress of weather radar system in Japan. It is believed that any discussion on it will be a reference for weather radar deployment and its QPE product in Nepal in coming days.

Keywords: Weather radar, rainfall, mountain, QPE, beam blockage, Nepal

\section{Introduction}

$T^{2}$ he South Asian country of Nepal is extensively diverse in term of topography (Fig 1). The Great Himalayas, complex mountains, hills and the plains (Terai) are home to this country. The elevation of the country ranges from less than 100m above sea level in the Terai, to the highest point on earth i.e. the summit of Mt. Everest at 8,848$\mathrm{m}$ all within a distance of about $150 \mathrm{~km}$ (North-South distance), resulting not only in dramatic difference in elevation, but also in climatic conditions ranging from sub-tropical to Arctic. About 80\% of its land occupies mountains; including hills to the higher Himalayas, which are located all around the country, with the highest peaks in the northern part (Fig 1). One example of such a complex variation in the three dimensional view is shown in the Fig. 2. It is clearly seen that several complex mountain peaks with gorges between them are scattered all around the region. Hence, in such complex topographic country, there exist more than 6,000 rivers and streams, with most of them originating from the higher Himalayas and mountains and flowing towards the Southern part of the country, i.e. from mountains to the Terai region in the country. Due to the sloppy topographic structure, rivers flow at higher speeds, reflecting a higher chance of flash floods. Moreover, due to the unpredictable weather phenomenon in this part of the world, Nepal is considered as one of the disasterprone countries in the world. It has experienced several natural catastrophes causing high economic and human losses every year. Heavy rains and storms are one of them, which cause severe flooding and trigger landslides that have a devastating effect on property, structure and human lives. Each year, floods cause immense damage to agricultural land, crops, human settlements and other physical properties. Since 1971, there has been a increasing number of significant losses of lives and livelihoods due to floods, every single year. Moreover, there are several number of glacier lakes located in the high mountains. Some of them are expanding their areas due to the melting of glaciers, which might be potentially dangerous if they burst (P.C. et al., 2013a). Common disasters in high mountains are avalanches and snow storms which are directly related with precipitation distribution.

The population density is higher in the southern and middle part of the country, whereas the Northern part has less population density due to the location of the higher Himalayas (Fig 3). Each year, the people of this country are affected by water related disasters. Rivers in Nepal mostly originate from the higher Himalayas or mountains and flow to the south direction of the country. Hence, flooding in rivers is a major concern at the middle and southern part of the country. Urbanization has been growing mainly in the middle and 
Southern part of Nepal, which has led to encroachment on the bank of rivers mostly in urban areas, and open lands of the city area are being covered by houses and concretes. Previous research has demonstrated that the flood-affected population of Nepal could increase in the future (Hirabayashi and Kanae, 2009; Maki et al., 2012). Moreover, the rainfall that causes these floods is becoming more variable and extreme, posing a greater risk from flood damage (Georgakakos, 2006; Kobiyama and Goerl, 2007). The patterns of precipitation in this mountainous region also trigger flash-floods, debris flow and landslides. It is a well known global phenomenon that highly localized, heavy rainfall triggers flash floods quickly. To understand and effectively manage such disasters, first, we need to get accurate information about the precipitation. An accurate measurement and forecasting of the precipitation, in terms of spatial and temporal basis across a region, is extremely important to mitigate water related disasters as well as related issues (Barros and Lang, 2003).

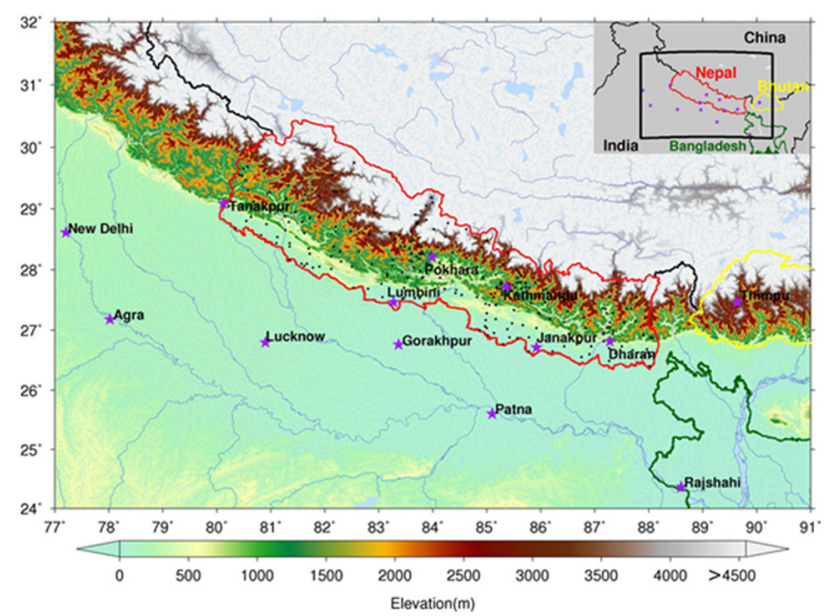

Figure1: Topography feature of Nepal in the Hindu Kush region. Black points over Nepal represent the meteorological stations.

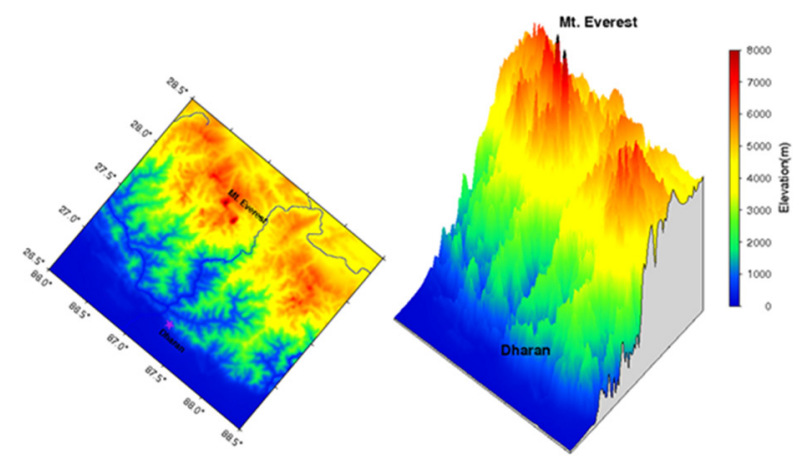

Figure 2: 2-D view (Left) and 3-D (right) of complex mountains view of eastern Nepal.

To monitor and to prevent the natural disasters caused by precipitation is primarily needed to understand the high resolution of precipitation measurement over such areas. This is also one of the important parameters to maintain the hydrological cycle. Precipitation is often considered spatially uniform over the catchment,

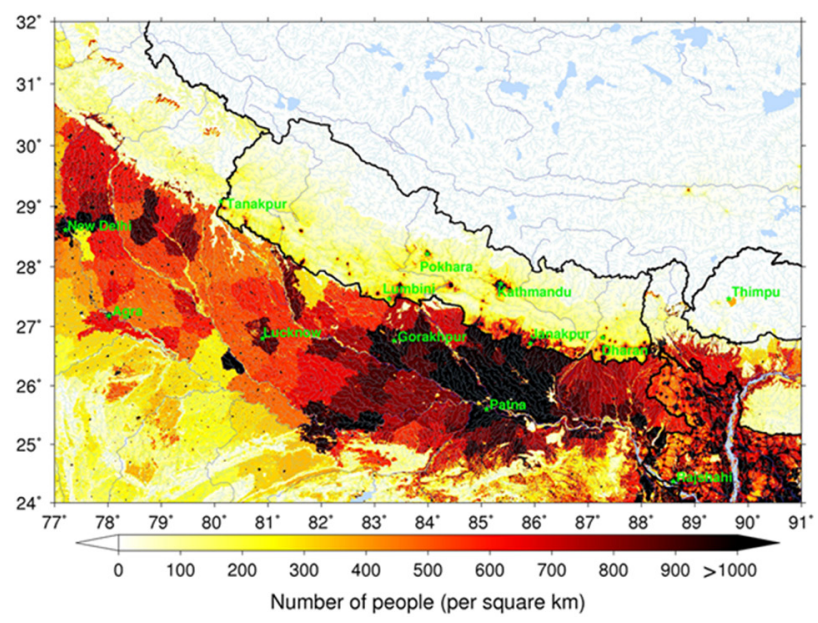

Figure 3: Estimated population distribution per grid square across the Hindu-Kush region based on World Pop continental dataset, April 2015

which is not usually the case. Rather, it is highly variable in both space and time. A traditional method of collecting precipitation data has been carried out by the conventional instrument "rain gauge", all over the world. There is no doubt that rain gauges provide precipitation data at the ground source with less error. There exist long records of precipitation data all over the world and all they represent is the point data. Based on this limited data, different kinds of interpolation method are used to get the spatial and temporal variability of precipitation. In many cases, interpolations do not always provide sufficiently precise rainfall distributions (Allegretti et al., 2012). Precipitation can vary over a small area as a result of changes in natural topography and atmospheric circulation (Barros et al., 2000). Austin et al. (2002) showed, for example, that during a storm, rainfall may vary by tens of millimeters per hour, from minute to minute, and over distances of only a few tens of meters. Practices on measuring rainfall in Nepal have been derived from rain gauge networks. Total land of Nepal is $147,181 \mathrm{sq} . \mathrm{km}$ and there are about 242 rain gauge networks. Of these, a few rain gauge stations have been deployed at accessible areas of mountainous regions as compared to plain and urban areas, according to the Department of Hydrology and Meteorology (DHM). Among them, some of the rain gauge networks collect rainfall amount in automatic mode while, most of them are in manual format. Distributions of these stations are very few, especially in the mountainous area. It is almost impossible to get the high resolution of rainfall data from these least uneven distributions of available networks. It is very interesting that most of the rain gauges in Nepal's mountainous areas are located at valley bottoms (Lang and Barros, 2002) and it is of course difficult to take measurement in the higher elevation of mountainous area on a regular basis. Few rain gauge networks can be seen in mountains regions of Nepal as compared to plain and urban areas (Rain gauge stations represent in black points in Fig. 1). Continuous measurement of 
precipitation data in high temporal resolution is still lacking in many parts of the country and their spatial distribution has been prepared based on some kind of an interpolation method. This might give serious errors other than the rain gauge station. Hence, spatial and temporal variation of rainfall based on such gauge networks may have a high chance of error. It should be noted that in such situation, hydro meteorological studies often fail to predict flash floods and landslides using modeling because of the scarcity of rain gauges, especially in mountainous areas.

To get the high spatial and temporal resolution of rainfall data, there has been considerable effort from several research agencies, universities, and private companies all around the world for a long time. As a result, there are several techniques available for estimating the spatial and temporal distribution of precipitation over a specific time interval, differently. Weather radar observations have been one of the alternative options used to estimate the spatial and temporal distribution of precipitation at a desired resolution. The most common types of weather radars are in S-, C- or $\mathrm{X}$-band wavelengths for the rainfall measurement. Although radar data have been available for almost half a century, operational assimilation has not been widely achieved to date. A few collections of high-quality data records from radar networks covering longer periods are available in some countries. Research using large amounts of precipitation time series data derived from weather radar observations has now begun (Suzuki et al., 2004; Sokol et al., 2009). The application of weather radar rainfall to hydro meteorological problems has been described by many researchers (Maki et al., 2005; P.C. et al., 2013b; P.C., 2017). Research has shown that gaugerecorded rainfall rates are in good agreement with rates estimated using X-band polarimetric weather radar over both flat and mountainous areas of Japan (Maki et al., 2005; Park et al., 2005b; P.C. et al., 2013b). Different types of radar have been used to record, monitor and forecast precipitation in several countries of this world for operational and research purposes. Unfortunately, rainfall estimation using weather radar system on operational basis has not started yet in Nepal. Nepal is expected to have its own fine resolution of weather radar rainfall product for the hydro meteorological application. It is important to understand the challenge and need of radar estimated rainfall for such a mountainous country. Therefore, in this study, we highlight the challenge and opportunities in estimating precipitation, using weather radar system over the complex geographic land in Nepal. Moreover, the application of spatial and temporal rainfall data from radar observation is also discussed in this study. It is believed that this paper shows some attention in deploying weather radar observation in Nepal in the coming days.

\section{Weather Radar Observation}

The concept of weather radar is not new. It was developed during World War II. After then, military scientists continued their work in developing first operational weather radars. Continuous research and improvements in this field have resulted in advanced types/bands of weather radars, with lesser uncertainties. Modern weather radars are mainly in conventional, Doppler or polarimetric system. Conventional radars measure only the amplitude information of the radio waves which have back-scattered from raindrops and returned to the radar (reflectivity factor), with which rain rates can be estimated. Doppler radars measure frequency information (Doppler frequency) in addition to the amplitude information, from which the radial velocity (Doppler velocity) of raindrops to the radar can be measured. Polarimetric radars enable the transmission of two types of radio waves; vertical and horizontal polarization, while conventional and Doppler radars can transmit only a single type. Various parameters can be obtained from the signals that are reflected from raindrops. All these radars do not directly measure rainfall. Instead, they measure the energy returned from a precipitation target.

As it is mentioned in the previous section that there are three band types of weather radars (S-, C- or $\mathrm{X}$-band wavelengths), they are mostly used in hydrometeorological field. Based on the country requirements and interest, different bands of weather radars have been deployed in different countries. S-band weather radars (wavelength of 8-15 $\mathrm{cm}$ and a frequency of 2-4 $\mathrm{GHz}$ ) are useful to cover near to far range weather observation and are not easily attenuated. It requires a large antenna dish and a large motor to power it. C-band radars (wavelength of 4-8 cm and a frequency of 4-8 $\mathrm{GHz}$ ) are well suited for detecting heavy rain at very long ranges (Up to $300 \mathrm{~km}$ ). The dish size does not need to be very large. The signal is more easily attenuated. The above given frequency allows the C-band radar to create a smaller beam width using a smaller dish. It also does not require as much power as a S-band radar. X-band radars (operate on a wavelength of $2.5-4 \mathrm{~cm}$ and a frequency of 8-12 GHz) represent a good compromise between range and reflectivity and cost. They can provide rain detection up to a range of $80 \mathrm{~km}$. They are used for studies on cloud development because they can detect the tiny water particles and also used to detect light precipitation such as snow. It is more sensitive than S or C-band radars, which are used for short range weather observations up to a range of $80 \mathrm{~km}$. X-band radar also attenuates very easily, so it is used for very short range weather observation only. Also, due to the small size of the radar, it can be portable like the Doppler on wheels. It is clear that each radar type has its own benefits and drawbacks. Among them, the polarimetric radar measurement is the newest weather radar observation. It can recognize and classify different types of precipitation 
like rain, hail, graupel and snow since it has a wavelength of $3 \mathrm{~cm}$. Such type of observation is already being operated by institutions/agency in the country of Japan. For example; National Research Institute for Earth Science and Disaster Resilience (NIED), Tsukuba has been operating polarimetric X-band multi-parameter radar and developing rainfall algorithm for hydrological and meteorological application since 2000 (Maki et al., 2005). The output of the weather radar parameters are horizontal polarization reflectivity $\left(\mathrm{Z}_{\mathrm{H}}\right)$, vertical polarization reflectivity $\left(Z_{V},\right)$ and differential reflectivity $\left(\mathrm{Z}_{\mathrm{DR}}\right)$. The specific differential propagation phase shift $\left(\mathrm{K}_{\mathrm{DP}}\right)$, is used for the quantitative precipitation estimates.

\section{Rainfall Estimation Principle}

A key issue in radar-based rainfall estimation is to identify the relationships between reflectivity (Z) and rain intensity (R). In ideal conditions, reflectivity is closely related to back scattered radar energy from raindrops in the atmosphere. A straight forward functional relationship between the two variables can be treated as

\section{$Z=a R^{b}$}

Where, $\mathrm{Z}$ is reflectivity $\left(\mathrm{mm}^{6} \mathrm{~m}^{-3}\right), \mathrm{R}$ is rainfall intensity $\left(\mathrm{mm} \mathrm{h}^{-1}\right)$, and $\mathrm{a}, \mathrm{b}$ are empirical parameters. Marshall and Palmer (1948) found that power law relation with the parameters $\mathrm{a}=200$ and $\mathrm{b}=1.6$. But, these values are slightly different based on type of precipitation and location itself. In general, the Z-R relationship is used to estimate rainfall rate in most of the weather radar observation. But, now a days, other polarimetric parameters $\left(\mathrm{Z}_{\mathrm{DR}}, \mathrm{K}_{\mathrm{DP}}\right.$ or both) including reflectivity are also used to estimate rainfall rate in different conditions and research shows that accurate estimation of precipitation is more reliable using such polarimetric parameters. The polarimetric X-band multi-parameter radar is a comparatively new method and is more popular due to its detailed information immediately after observation.

However, rain gauges and weather radars are the two sensors that can be used to measure the precipitation amounts. The weather radar has seen considerable interest from weather experts in continuous measurement of rainfall on spatial and temporal basis for operational forecasting of river flow, flash floods and landslides. Weather radar helps to improve our knowledge of rainfall fields, but radar rainfall fields are affected by systematic and local errors that should be corrected. Overall, the primary advantage of weather radar data lies in collecting precipitation amounts on both spatial and temporal basis with the desired interval time steps that cannot be measured by existing network of limited rain gauge networks.

\section{Weather Radar Products and its Application}

QPE from radar observations is not an easy task. It involves issues of complicated and sophisticated hardware engineering design with both electronic and mechanical subsystems; signal processing, propagation and interaction of electromagnetic waves through the atmosphere and with the ground, image analysis and quality control, physics of precipitation processes, optimal estimation and uncertainty analysis, database organization and data visualization, and hydrologic application (Krajewski and Smith 2002). The weather radar product can be used in short-term forecasts of precipitation for a specific location or a specific region, for e.g. weather services, media (Radio, TV), air services, road services, police, agriculture, construction companies, water management services, sports and private users. Weather radar observation in different band widths can provide higher resolution spatial and temporal variation of precipitation data on real time basis. Among them, X-band multi-parameter radar systems provide effective solution for high-resolution precipitation observations due to their small size and low demand in transmitter power with very short time period steps. In addition, they are more suitable for small range flood studies in complex terrain. According to Einfalt et al., (2004), requirements for application of weather radar data can be separated into two categories: 1) Technical requirements that include the sensitivity of the application on time, space and volume aspects of the delivered data and 2) Organizational requirements that refer to the safety of data availability in an operational context, cost effectiveness of data and support for data use.

Weather radar data can provide an extraordinary opportunity to improve our ability of observing extreme storms and quantifying their associated precipitation (Krajewski and Smith, 2002). Many hydrological applications come out using weather radar results and many research programs have shown the strengths and limitations of radar rainfall data (Einfalt et al., 2004). There are lots of progress and achievements that has been done using such radar products in Japan. For example: Polarimetric X-band multi-parameter radar of NIED can give three dimensional distribution of wind, rainfall amounts and can be used in real time flood risk mapping for the flood risk in the urban areas. X-band radar at NIED can also detect volume of water of radar covered areas which is very important to hydro-meteorological modelling of the catchments.

\section{Lesson Learned from the Radar Rainfall System in Japan}

One of the very highly developed countries, Japan is located in East Asia. Approximately 80\% of Japan is composed of hills and mountains. They can be seen everywhere in Japan. The highest mountain in Japan is the renowned Mt. Fuji (3775 m), which is commonly 
known as Fujisan. Most rivers in Japan originate in mountainous terrain, and have been serving as a backbone of Japanese life, culture, and agriculture for centuries. Rivers in mountainous regions are unstable because of the steep, narrow river valleys and highly variable precipitation. Many urban areas in Japan, as well as forested nature reserves, are located near rivers that flow from the mountains. Though the country Nepal is not highly developed, about $80 \%$ of the land is composed of complex mountains in both countries and there are many similarities in the contest of geographical land structures, culture and human settlements and disasters. Therefore, accurate estimates of precipitation in spatial and temporal basis play a key role in predicting and managing disasters in mountainous regions of both countries.

Remote sensing technologies are the most common methods used to measure precipitation all over the country in Japan. Different types of weather radars have also been used to record, monitor, and forecast precipitation in Japan for both operational and

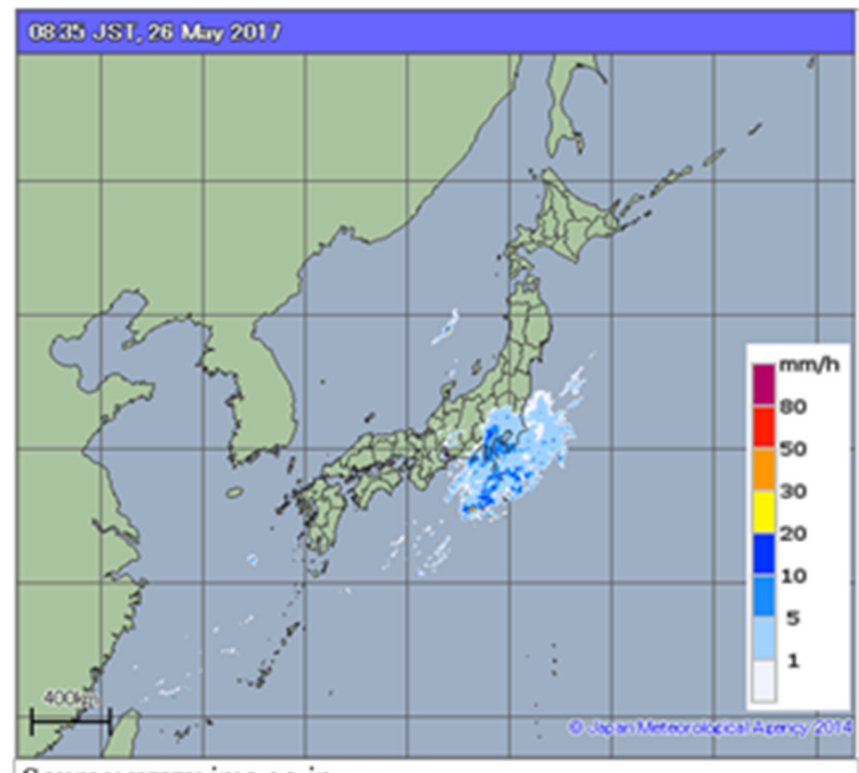

Source: www.jma.go.jp radars (JMA radar) across Japan to provide real time operational data (Nagata, 2011). To minimize errors in rainfall estimates, JMA constantly updates data using limited Automated Meteorological Data Acquisition System (AMeDAS) gauge stations (Sugiura, 2013). The Ministry of Land, Infrastructure, Transport and Tourism (MLIT) has established an X-band polarimetric radar network (XRAIN), which uses an operational data processing system developed by the NIED (Maki et al., 2005; Park et al., 2005a, b; Maesaka et al., 2011). XRAIN is composed of X-band MP (multi-parameter) radars, and has spatial and temporal resolutions of 250-m and 1-min, respectively. This product is one of the best highresolution radar rainfall systems in the world in terms of operational basis. Both JMA and XRAIN rainfall map are available to the public and private sector in real time through their website (Fig. 4). For the detail view of their product, Fig. 5 shows an example of the spatial distribution of rainfall using two different radar network systems, and clearly shows differences in the spatial distribution of accumulated rainfall.

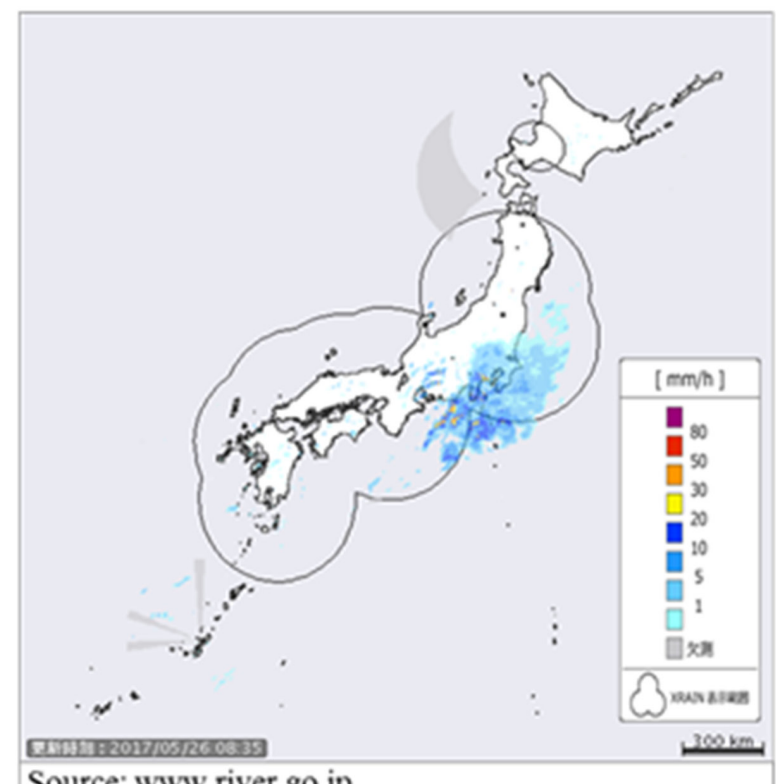

Source: www.river.go.jp

Figure 4: An example of radar estimated rain rate window for real time basis over Japan from JMA (Left) and MLIT (right) which are available on their website. JMA and MLIT use different weather radar to estimate rain rate in different spatial and temporal resolution

research purposes. Japan has a long history of weather radar observations. A weather radar committee was established in 1950 to promote the introduction of radar technology, and began conducting research using the first X-band weather radar with Plan Position Indicator (PPI) and Range Height Indicator (RHI). The Japan Radio Company (JRC) built the first Japanese $\mathrm{X}$-band weather radar in 1954. This was installed at the Meteorological Research Institute (MRI) in Tokyo. After having several sequences of continuous research and their testing on the radar system, nowadays, the Japan Meteorological Agency (JMA) produces 1000-m spatial and 5-min temporal rainfall using more than $20 \mathrm{C}$-band

\section{Radar-based Quantitative Precipitation Estimation (QPE)}

In Japan, weather radar observations at C-band and $\mathrm{X}$-band wavelengths that incorporate dual polarization technology are most common. Several output parameters can be obtained, including $\mathrm{ZH}, \mathrm{ZV}, \mathrm{ZDR}$, and $\mathrm{KDP}$, and each has associated benefits and limitations for estimating rainfall rates (Bringi and Chandrashekhar, 2001). C-band radars are suitable for large areas and are most commonly used for operational precipitation estimation, as these systems do not result in as much attenuation as other wavelengths. Research has shown that QPE using X-band polarimetric parameters has a 
good harmony with the rainfall rate obtained from rain gauge networks (Maki et al., 2005; Park et al., 2005b). Hence, rapid QPE with high accuracy is possible on high-resolution spatial and temporal basis. The beam width of X-band radar does not become wider than $\mathrm{C}$ - or S-band radars, because the observation range of $\mathrm{X}$-band is generally shorter than those of C- and S-band radars. However, although $\mathrm{X}$-band radar provides highresolution spatial and temporal rainfall estimates, there are still inherent uncertainties in radar parameters derived from these systems. Their main disadvantage is represented by the attenuation due to propagation through precipitation that determines important errors in radar rainfall estimation obtained from parameters derived from power measurements.

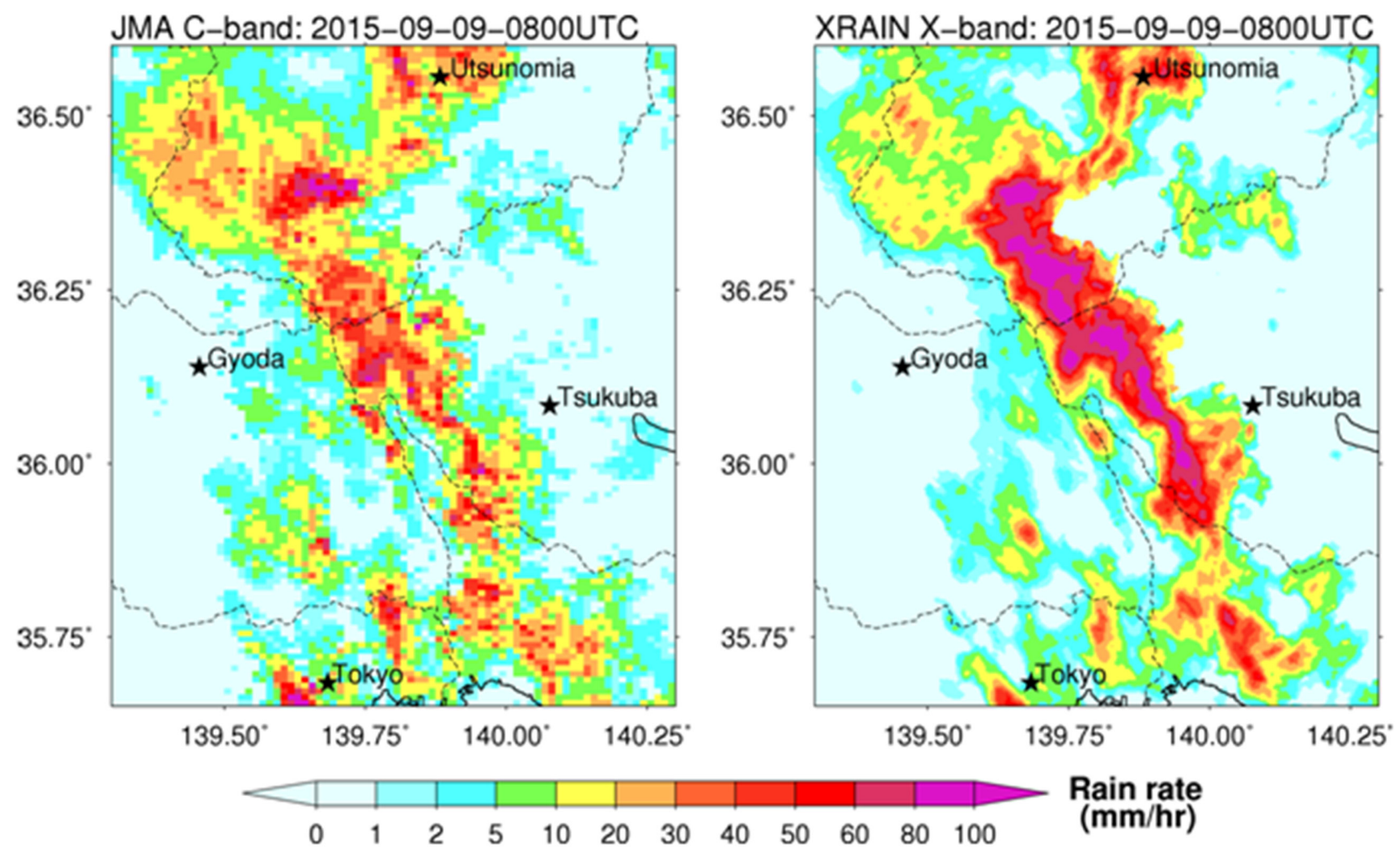

Figure 5: An example of estimated rain rate using C-band (right) and X-band (left) weather radar in Japan.

The signal attenuation error is a common problem associated with the use of weather radar for QPE (Park et al., 2005a; Maki et al., 2005; Kim et al., 2010). Different algorithms have been developed to eliminate the attenuation error for different radar bands in in various environments (Park et al., 2005b; Kim et al., 2010). Signal extinction area sometimes appears in X-band wavelengths. If extremely heavy rainfall passes over a radar site, the effective coverage range decreases to less than 10-km (Maki et al., 2012). This signal extinction problem can be solved by using data from entire radar observation networks (Kim and Maki, 2012). Park et al. (2005a) and Kim et al. (2010) corrected the attenuation effect in the Kanto region of Japan using $\mathrm{X}$-band polarimetric weather data (MP-X Ebina). Others problems in the use of radar data are beam blockage (mainly over mountainous regions), ground clutter, and anomalous propagation. In general, blockage and ground clutter problems are not as significant over flat areas as over more complex terrain. Various direct and indirect methods have been applied to different types of radar to correct errors caused by Partial Beam Blockage (PBB). But there is still no agreement regarding the most appropriate solution, and there have been few studies using X-band radar. The problem of beam blockage is a major issue affecting radar hydrology and meteorology in mountainous areas. In Japan, there has been limited research into the beam blocking effect. However, as it is an important source of error in Japanese radar data because of the presence of complex mountains ranges, a

new algorithm has been developed by P.C. et al. (2013b). It has been tested in the Hakone mountain region of Japan, as well as over the Shizuoka and Fujinomiya mountain regions (P.C. and Maki, 2014). This new algorithm shows good agreement with observed data, and it is believed that it will help to reduce the beam blocking effect over mountainous regions in Japan. Other polarimetric parameters, such as KDP and ZDR, may improve the accuracy of QPE (Maki et al., 2005; Park et al., 2005b). It is believed that uncertainty in KDP remains high regardless of the maximum percentage of Beam Blockage Rate (BBR). Further research on KDP over mountainous regions is therefore needed. Advance research on these polarimetric variables has been conducting from different research institutes, 
universities and other private companies in Japan and much progress has been made in this field (Iwanami et al., 2001; Iwanami et al., 2003; Maki et al., 2005; Park et al., 2005a, b; Maesaka et al., 2011; Kim and Maki, 2012; P.C. et al., 2013b; P.C. and Maki, 2014) to enhance the quality of radar estimated rainfall over mountainous regions in Japan. Hence, high accuracy of QPE product are available in real time basis in Japan and several studies have verified on it (Maesaka et al., 2011; Kim and Maki 2012; Maki et al., 2012; P.C. et al., 2016).

Tokyo metropolitan area is the world's most populous metropolitan area and its total population is approximately 30 million. It is a high chance that millions of people are inherently vulnerable to torrential rainfall especially in such city areas. In such case, quick information of forecasting precipitation in such areas is always important. But, long range radar measurements (C-band or S-band) may have chance of overshooting the precipitation echo over an area. To address these issues, a test bed with X-band radar networks has been started in the Tokyo metropolitan area since a long time so that a monitoring and predicting system of extreme phenomena can be issued on a real time basis to prevent the disasters and the reduction of damage in those situations. However, to use it for practical purposes, intensive research should be conducted. Nowadays $\mathrm{X}$-band radars represent a cost- effective solution because these radars are much cheaper (in direct cost, infrastructure and maintenance costs) than traditional C-band or S-band radars with the same beam width. $\mathrm{X}$-band radars can offer a viable solution to fill gaps of these networks in mountainous regions. Moreover, the application of weather radar for hydrometeorological research in Japan has been described by many scientists in their studies (Maki et al., 2005; Kato and Maki 2009; Hirano and Maki, 2010; P.C. et al., 2015; P.C. et. al., 2016).

\section{Challenges in Weather Radar Deployment in Nepal}

As mentioned in the previous section, Nepal has a very complex topography and weather radar observations have not yet started operationally. Therefore, the experience and research on weather radar observation and the QPE product in Japan can definitely provide some ideas in the deployment of weather radar observation and their QPE product, apart from the application to hydro meteorological fields. Depending on the country needs, policy and availability of band width, the type of weather radar would be defined. In Japan, different types of weather radars have been considered for research purpose. But, X- and C-band have been used to estimate radar rainfall all over the country for operational purpose. C- and S-band meteorological long-range radars are able to monitor rain fields over wide areas; they do not provide a sufficiently high spatial and temporal resolution, and have high purchase and maintenance costs. X-band radars, on the other hand, can be useful for observing rainfall events at higher resolutions. For this reason, the number of X-band dual polarization radar networks is increasing nationwide in Japan. Any type of weather radar can be used to estimate the precipitation over Nepal. But it is very important to understand their advantages and disadvantages for Nepal. We discuss major common problems in weather radar observation system based on topography and the economic aspect in the next sub-section, which may be a good reference for planners, government agencies and others in Nepal.

\section{Beam Blockage Problem}

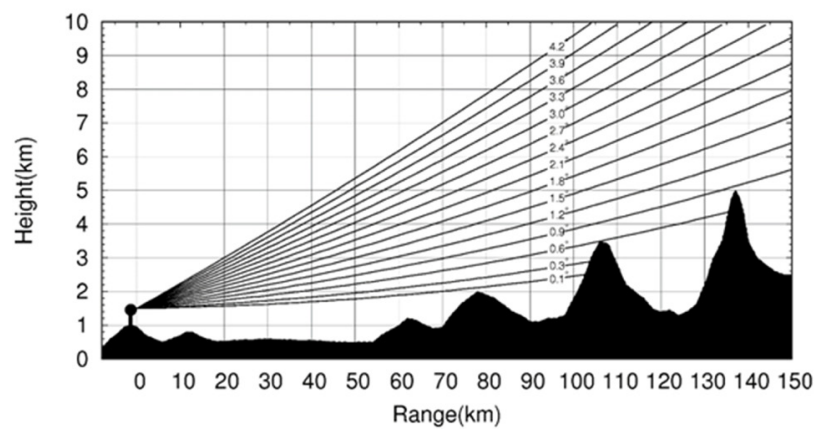

Figure 6: Beam height of radar beam with respect to range profile in a complex mountain environment.

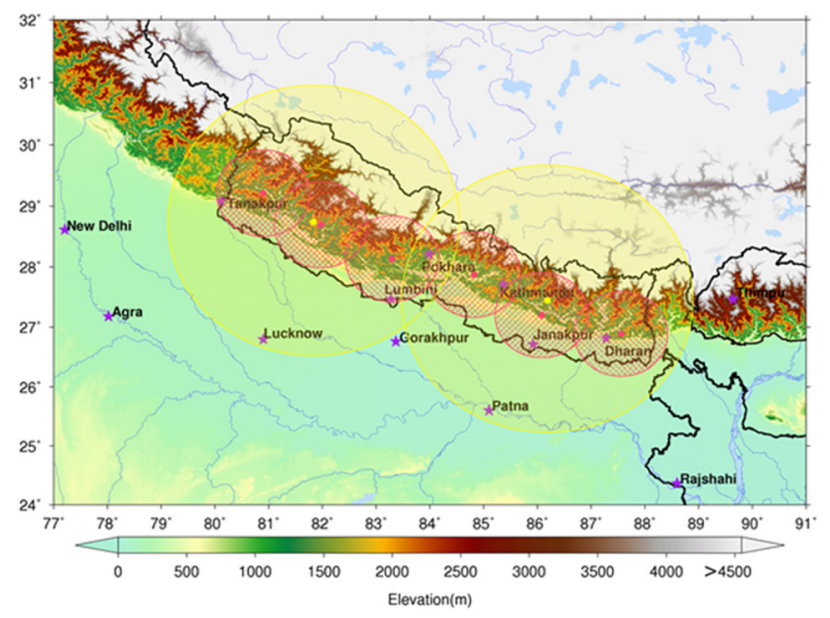

Figure 7: Illustration of weather radar coverage networks in Nepal. Yellow circles denote C-band weather radar coverage range of $250-\mathrm{km}$ and pink circles denotes X-band weather radar with $80-\mathrm{km}$ coverage range.

Problems in radar data accuracy are inherent in mountainous regions because of the height, shape and orientation of mountains. Estimated radar rainfall is considered to be equal as of rainfall at the ground stations. Hence, lower elevation angle of the weather radar is always preferred to estimate rainfall rate. In the case of lower elevation angle of weather radar observation, PBB correction should be a high priority, especially in a mountainous country like Nepal. Studies 
show that the effects of PBB seriously underestimate the rainfall rate. Many studies have shown that an effective beam blockage correction scheme is essential to ensure that QPE in mountainous regions are accurate (Maki et al., 2005; P.C. et al., 2013b; P.C. and Maki, 2014). In general, a problem of beam blockage and ground clutter over the flat area is not significant as compared to the complex terrain. PBB is common especially in the mountainous region for any type of weather radars (Fig. 6). Therefore, PPB is one of the most important problems especially over the mountain region for the QPE.

In Nepal, there are complex terrain, especially in the northern part of the country (see Fig. 2), But, the southern part of the country represents a flat area (Terai). Hence, except the extreme southernmost part of the country, almost all the parts have mountains, valleys, gorges etc. Based on the geographical condition of the country Nepal, areal coverage distance from South to North part should be greater than $150 \mathrm{~km}$. Therefore, to cover the country's land and its periphery, installation of weather radar may be suitable in the central part of the country. Of course, there are valleys; mountains peaks etc. which all are located from the Central to the Northern part of the country. In Nepal, several mobile and other communication towers are deployed at the top of the mountain peaks. Therefore, it could be possible that installation of radars might be at the top of mountains which will definitely support omitting the beam blockage in some parts of the hilly terrain. Some part, though, may easily suffer from the beam blockage (Fig. 6) due to vast mountain peaks. Hence, slightly increasing the elevation angle may be necessary to reduce the chance of $100 \%$ beam blockage. In the case of partial beam blockage, various direct and indirect methods can be applied to correct errors caused by PBB. In Japan, a new method to address PPB is being successfully tested (P.C. et al., 2013b; P.C. and Maki, 2014) which could be one of the solutions to address PBB in Nepal.

\section{Other Problems}

Several other errors may occur during the radar observation. For example: noise, ground clutters, nonmeteorological echoes, data calibration etc. need be addressed during the data processing stage itself. To maintain the quality control of the observed data, a series of procedures i.e. specific software/tools module have been used in preprocessing of radar data. One of the common problems on the weather radar is the signal attenuation error which has acknowledged by many researchers (Park et al., 2005a; Maki et al., 2006; Kim et al., 2010) in Japan. Due to the rain environment of the atmosphere, signal of radar observation may have a high chance to be attenuated. Different types of algorithms have been developed to eliminate the attenuation error on different bands of radar in the dissimilar environment. Carey et al. (2000) studied the attenuation effect utilizing differential propagation phase to estimate both the horizontal and differential attenuation at C-band. The method they used is based on empirical correction using differential propagation phase. Park et al. (2005a, b) and Kim et al. (2010) studied on the correction of attenuation effect using $\mathrm{X}$-band polarimetric weather data. They adapted and modified the self-consistent method proposed by Bringi et al. (2001) to enable attenuation correction and showed a good agreement with the ground truth data over the flat area. Hence, any one of these methods can be applied to correct the attenuation effect.

\section{Discussion and Conclusion}

In recent times, rapid urbanization close to mountains, infrastructure along Mountain Rivers, and the number of sources of supply water in mountainous regions have all been increasing. All these features are directly or indirectly linked to the characteristics of precipitation. Disasters caused by precipitation in mountainous regions and nearby areas are common due to their weak and unstable geological structure. Moreover, the occurrence of narrow valleys surrounded by high relief makes disaster management in mountainous regions very difficult. Therefore, to minimize the risk of disaster induced by precipitation, there is a need to estimate the temporal and spatial variations in the amount of precipitation using weather radar observation. As discussed in the previous section, there are different kinds of weather radars that are available and each of them has its advantage or disadvantage. But, deployment of weather radar system is basically depended on the nation's policy and availability of band width.

Different types of weather radars have been used to estimate the amount and intensity of rain over the land surface. There are several options available for estimating the spatial and temporal distribution of precipitation over a specific time interval, including the most common types of weather radars. Different countries use different types of weather radar observation depending upon their needs and demand. In the urbanized area of the mountainous country of Japan, X-band and C-band radars observation have been deployed and provides QPE product in real time as an operational basis. World Meteorological Organization (WMO) states that the number of X-band weather radars in use in WMO member countries has grown to almost $20 \%$ of the total counted radars. This increase is a clear signal of the power of an emerging technology that guarantees high observational skills as well as reduced installation and maintenance costs, and that has also been shown to be particularly suitable for mobile radar applications, compared to more widespread systems such as the conventional C- and S-band radars. General ideas about the number of radar observation stations in Nepal in different band width are shown in the Fig 7. In this paper, we have taken an example of Japan, so that area coverage of S-band weather radar observation is not shown. If the 
C-band radar observation is installed, then at least two C-band radar will be needed to cover the main important area of the country, but if X-band is to be considered for the deployment, then at least 6 radar observations are needed to cover the main part of the country. It should be noted that these two types of radar observation provides different spatial and temporal resolution of rainfall. Occurrences of convective precipitation are frequent, especially in pre-monsoon, monsoon and postmonsoon seasons in Nepal. In such case, high spatial and temporal resolution of QPE would be important for hydro meteorological application.

Due to the presence of complex terrain in Nepal, the radar beam can experience partial or total blocking and over shooting, even with the use of C-band radar. As a consequence, in regions characterized by a complex orography, the coverage of operational C-band networks is often inadequate or even non-existent. This problem often occurs in Japan and European countries. Nowadays $\mathrm{X}$-band radars represent a cost- effective solution because these radars are much cheaper (in direct cost, infrastructure and maintenance costs) than traditional C-band or S-band radars with the same beam width. For those cases, adding of X-band radars networks can offer a viable solution for having QPE system. Their main disadvantage is represented by the attenuation due to propagation through precipitation that determines important errors in radar rainfall estimation obtained from parameters derived from power measurements. The use of dual polarization techniques in X-band radar systems has provided solutions to mitigate the impact of attenuation.

There are more than $30 \mathrm{X}$-band dual polarimetric and $20 \mathrm{C}$-band weather radar observations across Japan and have been deployed for estimating precipitation with high accuracy for a long time. Indeed, having weather radars only in Nepal is not enough for its effective uses. Training and recruitment of very good operational staff, radar engineers, maintenance staff and overall coordinating person are the key sources for the advanced weather radar operation system. Hence, experience, research and technology development in the weather radar field of Japan would be helpful for the progress of weather radar system and their QPE product in a mountainous country like Nepal.

\section{Acknowledgements}

The authors acknowledge the support of the National Research Institute for Earth Science and Disaster Prevention Resilience (NIED). We wish to thank Dr. Ryohei Misumi, NIED for his valuable suggestions on an earlier version of the manuscript.

Shakti P.C., PhD, is a researcher at Storm, Flood and
Landslide Research Division National Research Institute for Earth Science and Disaster Resilience (NIED), Tsukuba, Japan. His background is broadly connected with hydrology and meteorology. Specifically, he is interested in the radar hydrometeorology, probabilistic hydrological forecasting, precipitation now casting, and glacier and water resources.

\section{Corresponding E mail: shakti.pc@gmail.com}

Masayuki Maki, $P h D$, is a professor at the Research and Education Center for Natural Hazard, Kagoshima University, Kagoshima, Japan. He is a pioneer in the field of development of Multi parameter weather radar networks in Japan. His research interests include the application of polarimetric weather radar to the quantitative precipitation estimation and forecasting. Recently he started research on volcanic ash detection using polarimetric radar.

\section{Email:maki@gm.kagoshima-u.ac.jp}

\section{References}

Allegretti M, Bertoldo S, Prato A, Lucianaz C, Rorato O, Notarpietro R, Gabella M. 2012. X-band mini radar for observing and monitoring rainfall events. Atmospheric and Climate Sciences 2: 290-297.

Austin GL, Nicol J, Smith K, Peace A, Stow D. 2002. The space time variability of rainfall patterns: implications for measurement and prediction. Western Pacific Geophysics Meeting. AGU: Wellington, H42A-02; wp35.

Barros AP, Joshi M, Putkonen J, Burbank DW. 2000. A study of the 1999 monsoon rainfall in a mountainous region in central Nepal using TRMM products and rain gauge observations. Geophysics Research Letter 27: 3683-3686.

Barros AP, Lang TJ. 2003. Monitoring the Monsoon in the Himalayas: Observations in Central Nepal. Monthly Weather Review 131: 1408-1427.

Bringi VN, Chandrashekhr V. 2001. Polarimetric Doppler Weather Radar: Principles and Applications. Cambridge University Press.

Bringi VN, Keenan TD, Chandraseker V. 2001. Correcting C-band radar reflectivity and differential reflectivity data for rain attenuation: A self-consistent method with constraints. IEEE Transactions on Geoscience and Remote Sensing. 39: 1906-1915.

Carey L D, Rutledge S A, Ahijevych D A, and Keenan T D. 2000. Correcting propagation effects in C-band polarimetric radar observations of tropical convection using differential propagation phase. Journal of Applied Meteorology 39: 1405-1433.

Einfalt T, Arnbjerg-Nielsen K, Golz C, Jensen NE, Quirmbach M, Vaes G, Vieux B. 2004. Towards a roadmap for use of radar rainfall data in urban drainage. Journal of Hydrology 299: 186-202.

Georgakakos KP. 2006. Analytical results for operational flash flood guidance. Journal of Hydrology 317: 81103.

Hirabayashi Y, Kanae S. 2009. First estimate of the future 
global population at risk of flooding. Hydrological Research Letters 3: 6-9.

Hirano K, Maki M. 2010. Method of VIL calculation for $\mathrm{X}$-band polarimetric radar and potential of VIL for nowcasting of localized severe rainfall -Case study of the Zoshigaya downpour, 5 August 2008. SOLA 6: 89-92.

Iwanami K, Le Bouar E, Testud J, Maki M, Misumi R, Park SG, Suto M. 2003. Application of the rain profiling algorithm ZPHI to the X-band polarimetric radar data observed in Japan. Preprints 31 st Conference of Radar Meteorology, American Meteorological Society: Seattle; 274-276.

Iwanami K, Misumi R, Maki M, Wakayama T, Hata K, Watanabe S. 2001. Development of a multiparameter radar system on mobile platform. Preprints 30th International Conference of Radar Meteorology, American Meteorological Society: Munich; 104-106.

Kato A, Maki M. 2009. Localized heavy rainfall near Zoshigaya, Tokyo Japan on 5 August 2008 observed by X-band polarimetric radar -Preliminary analysis. SOLA 5: 89-92.

Kim DS, Maki M, Lee DI. 2010. Retrieval of threedimensional raindrop size distribution using X-band polarimetric radar data. Journal of Atmospheric and Oceanic Technology 27: 1265-1285.

Kim DS, Maki M. 2012. Validation of composite polarimetric parameters and rainfall rates from an $\mathrm{X}$-band dual-polarization radar network in the Tokyo metropolitan area. Hydrological Research Letter 6: 7681.

Kobiyama M, Goerl RF. 2007. Quantitative method to distinguish flood and flash flood as disasters. SUISUI Hydrological Research Letters 1: 11-14.

Krajewski WF, Smith JA. 2002. Radar hydrology: rainfall estimation. Advances in Water Resources 25: 13871394.

Lang TJ, Barros AP, 2002: An investigation of the onsets of the 1999 and 2000 monsoons in central Nepal. Monthly Weather Review 130: 1299-1316.

Maesaka T, Maki M, Iwanami K. 2011. Operational rainfall estimation by X-band MP radar network in MLIT, Japan. Preprints: 35th Conference on Radar Meteorology, September 26-30, 2011 Pittsburgh, USA, 11-142.

Maki M, Iwanami K, Misumi R, Park S, Moriwaki H, Maruyama K, Watabe I, Lee D, Jang M, Kim H, Bringi V, Uyeda H. 2005. Semi-operational rainfall observations with X-band multi-parameter radar. Atmospheric Science Letters 6: 12-18.

Maki M, Maesaka T, Kato A, Kim DS, Iwanami K. 2012. Composite rainfall map with X-band polarimetric radar network and $\mathrm{C}$-band conventional radar. Indian J Radio Space Phys 41: 461-470.

Marshall JS, Palmer WM. 1948. The distributions of raindrops with size. Journal of Meteorology 9: 327-
332.

Nagata K. 2011. Quantitative Precipitation Estimation and Quantitative Precipitation Forecasting by the Japan Meteorological Agency. Technical Review No. 13 RSMC Tokyo-Typhoon Center. 37-50. http://www. jma.go.jp/jma/jma-eng/jma-center/rsmc-hp-pub-eg/ techrev/text13-2.pdf. Last access June 1, 2015.

P.C. S, Pradhananga D, Ma W, Wang P. 2013a. An overview of Glaciers distribution in the Nepal Himalaya. Hydro Nepal: Journal of Water, Energy \& Environment 13: 20-27.

P.C. S, Maki M, Shimizu S, Maesaka T, Kim DS, Lee DI, Iida H. 2013b. Correction of reflectivity in the presence of partial beam blockage over a mountainous region using X-band dual polarization radar. Journal of Hydrometeorology 14: 744-764.

P.C. S, Maki M. 2014. Application of a modified digital elevation model method to correct radar reflectivity of X-band dual-polarization radars in mountainous regions. Hydrological Research Letters 8: 77-83.

P.C. S, Misumi R, Nakatani T, Iwanami K, Maki M, Seed AW, Hirano K. 2015. Comparison of rainfall nowcasting derived from the STEPS model and JMA precipitation nowcasts. Hydrological Research Letters 9: 54-60.

P.C. S, Misumi R, Nakatani T, Iwanami K, Maki M, Maesaka T, Hirano K. 2016. Accuracy of quantitative precipitation estimation using operational weather radars: a case study of heavy rainfall on 9-10 September 2015 in the East Kanto Region, Japan. Journal of Disaster Research 11: 1003-1016.

P.C. S. 2017. Quantitative precipitation estimation and hydrological modeling in Japan. Journal of Japan Society of Hydrology and Water Resources 30: 6-17.

Park SG, Bringi VN, Chandrasekar V, Maki M, Iwanami K. 2005a. Correction of radar reflectivity and differential reflectivity for rain attenuation at $\mathrm{X}$ band. Part I: Theoretical and empirical basis. Journal of Atmospheric and Oceanic Technology 22: 1621-1632.

Park SG, Maki M, Iwanami K, Bringi VN, Chandrasekar V. 2005b. Correction of radar reflectivity and differential reflectivity for rain attenuation at X band. Part II: Evaluation and application. Journal of Atmospheric and Oceanic Technology 22: 1633-1655.

Sokol Z, Bliznak V. 2009. Areal distribution and precipitation-altitude relationship of heavy short-term precipitation in the Czech Republic in the warm part of the year. Atmospheric Research 94: 652-662.

Sugiura I. 2013. Very-short-range forecast of precipitation in Japan. 14th annual WRF users's workshop. 24-28 June 2013, Colorado, USA.

Suzuki,Y, Nakakita E, Hasebe M, Ikebuchi S. 2004. Study on rainfall-topography relationships in Japan with regard to the spatial scale of mountains slopes, Proc. of 6 th Int. Symp. On Hydrological Applications of Weather Radar, Melbourne, Australia, 8pp. 